\title{
Legal Research on the Right to Rest of Laborers
}

\author{
Min Song ${ }^{1}$ \\ ${ }^{1}$ School of Law, Qingdao University of Science and Technology, Qingdao, China \\ Correspondence: Min Song, School of Law, Qingdao University of Science and Technology, Qingdao, China. \\ E-mail: 1318169157@qq.com
}

Received: June 2, 2016 Accepted: July 16, 2016 Online Published: August 30, 2016

doi:10.5539/jpl.v9n7p214 URL: http://dx.doi.org/10.5539/jpl.v9n7p214

\begin{abstract}
In 2015, the central government issued a document on building the harmonious labor relations, which emphasized the right to rest of workers and rectified the current severe imbalance of labor relations. This document released a signal to guarantee the sustainable development of the labor force for the future. These measures, such as relative departments perfecting the legislation and law enforcement, the trade union performing their duties actively, employing units and workers raising their awareness and enhancing mutual understanding and branches of the government cooperating, can realize the right to rest of workers to the greatest extent possible.
\end{abstract}

Keywords: laborers, the right to rest, harmonious laborer relations

\section{Introduction}

Peking University Center of Social Survey Research published the Research Report on China's Balanced Workplace Index in 2012 showing that at present, per capita working time was 8.38 hours a day; 30.3\% of workers worked more than 10 hours, even 16 hours at length. The figures above were closely to meet the global survey of working time released by Regus. Regus's survey indicated that $27 \%$ of office workers worked 9 to 11 hours a day; 5\% more than 11 hours in China. ${ }^{1}$ Therefore, China, over Japan and South Korea, has become one of the world's longest working time countries. In addition to working hours, about $30 \%$ of workers would take unfinished work home. The boundary between office and house has become increasingly blurred. At the same time, working overtime almost is the prevailing issue in all walks of life, especially in IT industry, scientific research institutions and professional occupation, such as police, doctors and accountants. All walks of life and people of all ages are facing the risk of varieties of diseases because of overstrain. It can be said that our workers spend their life time creating wealth for our country and the world, but the price is heavy.

According to the Chinese Health Data, up to $76 \%$ of white-collar workers there are in sub-health status in Chinese mainstream cities; about $60 \%$ are in the state of overwork ${ }^{2}$; less than $3 \%$, however, are healthy both in physical and mental ${ }^{3}$. In fact, the law of our country has clearly stipulated the issue of workers' overwork and rest: first of all, the Constitution grants workers the right to rest, and attaches the same importance as citizens' political rights, the right to personal freedom and the right to material assistance to it. Working time shall not be more than 8 hours a day, 40 hours a week ${ }^{4}$. Laborers who have kept working for one year and more shall be entitled to annual vacation with pay. The employing unit may extend working hours due to the requirements of its production or business after consultation with the trade union and laborers, but the extended working hour for a day shall generally not exceed 1 hour; if such extension is called for due to special reasons, the extended hours shall not exceed 3 hours a day under the condition that the health of laborers is guaranteed. However, the total extension in a month shall not exceed 36 hours $^{5}$.

The law's provisions are quite clear and comprehensive. However, why overwork is still an increasingly serious problem nowadays? Why workers' right to rest cannot be guaranteed? What is it that makes laborers work even

\footnotetext{
${ }^{1}$ http://news.21cn.com/caiji/roll/a/2012/0501/00/11676886.shtml, May, $3^{\text {rd }} 2015$

${ }^{2}$ http://ying-wy.blog.163.com/blog/static/440592682011315105536460/, April, $20^{\text {th }} 2015$

${ }^{3} \mathrm{http} / / / \mathrm{www}$. raincent.com/content-10-3272-1.html, April, $24^{\text {th }} 2015$

${ }^{4}$ Article 3 of Provisions of the State Council on Working Hours of Workers and Staff,

${ }^{5}$ Article 41 of Labor Law of People's Republic of China
} 
with extreme overwork and why does death from overwork happen so frequently? We need to know answers to these all question and root causes.

\section{The Factors of Current System}

\subsection{The Lack of Laws and Regulation Cannot Effectively Protect the Right to Rest of Workers}

Although the Constitution and Labor Law have clearly stipulated working hours, rest and vacations, these Provisions are fundamental and principled. It is rather easy for employing units practicing standard working time system to carry out 8-working-hour system; but there is no specific criterion about uncertain working time system and calculating working hour synthetically. As for different industries and different nature of the workers, how to execute the 8-hour-working system? There is no specific and actionable provision, according to current Labor Law and other relevant laws and regulation, to enforce. Law enforcement departments lack the positive initiative to take measures if employing units violate provisions of working hours and there are no specific penal and deterrent provisions to guide them to supervise and enforce. Workers tend to fall into the dilemma of the burden of proof and high cost to safeguard legal rights after their right to rest is infringed because of lack of the judicial remedy provisions. Especially, for workers who die from overwork, the next of kin cannot receive indemnity and compensation timely, because no specific criteria can be in use for reference to confirm, and at present, death from overwork is not brought into industrial injury insurance.

\subsection{The Absence of Organizing Work of Trade Union Causes Workers' Right to Rest Becoming Castles in the Air}

As workers' representative, in addition to representing workers' reasonable demands and negotiating with employing units to find the balancing interests of both sides, the trade union should protect workers' right to rest and help them to safeguard legal rights. However, due to the well-known reasons, the trade union fails to perform its duties, including failing to protect workers' right to rest, speak for workers, which, as a result, exacerbates the loss of the right and makes the trade union fall into an awkward situation and cannot give full play to its functions.

\subsection{The Design of Salary System Is not Reasonable}

Wage forms, under the condition of market economy, belong to employers' wage distribution right. Many employing units usually practice the mixed payment system although there are varieties of employing units and different laborers. The mixed payment system is based on the payment by the hour called base pay or basic salary for salary calculation and this part only accounts for a small proportion in total salary. Payment for additional work done outside of regular working hours can be paid by bonuses, allowance, overtime premium, which can promote labor productivity, but also a strange phenomenon comes out where those extra pay are higher than base pay. Therefore, laborers have to sacrifice their rest time for more wages. Although the State has wage control right, the right do not regulate the specifics about payment system, and then cannot play the role in regulating and controlling wages fundamentally.

\section{The Factors of Current Situation}

\subsection{Workers Lack Adequate Awareness on Their Own Right to Rest}

First of all, workers do not want to rest, which can be divided into two cases. One is social factors. China's tradition and mainstream value are that workers should love their jobs and be devoted. Therefore, overwork and going on working in spite of illness are normal state for them. Industrious and hard-working are typical characteristics of laborers, especially advocating working patterns of "day and night", and " $5+2$ ". Flipping through the media reports, we can find that words like "working as diligently over a decade as doing one day", "sacrificing rest time to work" etc. are usually used to describe model workers, whose right to rest, in fact, are really kidnapped to some extent. Of course, a lot of workers think that they are young and healthy and it's nothing and not a problem if they rest less to work hard for several years ${ }^{6}$. But they do not know the idea would lay hidden danger for death from overwork.

The other is wage factor. The work itself is not with high technology in those enterprises implementing the mixed salary system and piecework time system. Workers once get used to it, the physical strength is obviously essential. As long as you are willing to spend time and work hard, you can get competitive satisfied salary. Working more and fast is the only choice for workers. Enterprises do not even need to force workers to work overtime, do not need to pay more, because in this case, in order to get more, workers are not willing to rest, and some workers even save their toilet time and eating time, not to mention to holidays. This approach seems reflects "more pay for more work" and "workers' different amount of work", but actually it is a kind of

\footnotetext{
${ }^{6}$ The Poll conducted by Nan-Fang Media and gd.qq.com
} 
exploitation. Enterprises use psychological effect of "more pay for more work" and let workers voluntarily give up the right to rest to work overtime.

Second, workers do not dare to rest. To find a relatively decent job or to get a fairly satisfied salary is the pursuit of every worker. However, it comes to be difficult to find a job, which seems to become a social problem in recent years overnight. Different groups are facing the same dilemma, including both the college students and migrant workers. In order to gain a foothold in the workplace, to get the boss's recognition, once getting a job, the worker has no advantage to negotiate with the boss over conditions, and only talks about contributions and voluntarily sacrificing rest time. Otherwise leaving immediately is almost the only result.

Third, workers cannot rest. Some projects have to be done by a team, such as project research in IT industry and project auditing in audit industry. In the team, all the members have their own definite tasks to be achieved within limited time. Working overtime and even sleeping directly in their own or the clients' offices are often a matter of normal. As a member of the team, if you want to rest, you will increase the workload of other colleagues. Therefore, many workers, even if being sick, insist on working rather than rest because they are not willing to give the team some troubles. Pan Jie, with master degree of Shanghai Jiao-Tong University, worked in a famous international accounting firm. After just half a year, she died from overwork. Because of the task, she had no time to rest and suffered from acute meningitis. She waited until that disease got worse. Obviously, she missed the best treatment time and then died. To workers, this is a tragedy; to the society, this is a loss.

\subsection{Enterprises Pay Little Attention to the Workers' Right to Rest}

They need develop and must control cost firstly if they want to gain a firm foothold and remain invincible in the fierce competition. Among many costs, labor cost attached to workers is the most controllable. The simplest way to reduce labor costs is to let workers overwork and give them less rest. Even in some companies, working overtime is their corporate culture. At the same time, the illegal cost caused by letting workers overwork excessively is very low. There is no effective punishment measures for the illegal enterprises even if they are reported. Therefore, enterprises do not have to worry.

China has been taking the development road of manufacturing industry, featured by labor-intensive over the past 30 years. Its economic takeoff relies on many labor-intensive enterprises exploiting labor resources, which is the most abundant but cheapest in the world. Those enterprises make super profit through making the most of every second. Hence, workers' right to rest is ignored intentionally or unintentionally. Under China's existing market environment and policy, all the costs of the enterprises management, including the system cost and the invisible cost, are quite high, which means enterprises' profit space is further compressed objectively and their living environment is not optimistic. In fact, the entrepreneurs are also a high risk group of death from overwork. Of course, enterprises' pursuit of profit is understandable and beyond reproach, and the country also needs develop. But this cannot be a reason for infringing workers' right to rest. This kind of mode of operation is like draining the pond to get all the fish and will consume great loss of human resources in enterprises' productivity, which is not beneficial for enterprises' sustainable development in the long run.

\section{Guarantee Workers' Right to Rest Sufficiently}

In 2015, the central government issued a document on building a harmonious labor relations requiring that companies protect employees' right to rest and holidays effectively, improve and implement national regulation on working time, national holidays, memorial days, annual leave with pay, standardize employing units' examination and approval administration of special working time system, and supervise and urge companies to arrange for workers to take a break based on law. The central government emphasized and paid attention to the right to rest of workers once again, not only rectifying the current serious imbalance of labor relations, but also releasing a signal to guarantee the sustainable development of the labor force for the future. The vision where the government improves the working conditions of workers, like more rest and vacation, is good, but how to make good policy into reality, so that the right to rest from "paper" into "reality"? How to let laborer's right to rest not "rest"?

\subsection{The Mechanism of Workers' Right to Rest Should Be Perfected}

Good law is the premise of good governance. It is urgent that the matching specific laws and regulation be issued on laborer's right to rest based on some international human rights conventions, such as Universal Declaration of Human Rights and International Covenant on Economic, Social and Cultural Rights, and some domestic laws, such as Constitutional Law and Labor law. Although these conventions and laws have stipulated generally, there needs to be more details supporting them.

First, the systems of working hours, rest and vacations of Labor Law protects laborer's right to rest from both 
positive and negative aspects respectively. Therefore, the competent authority should strictly make approving measures of uncertain working time system, calculating working hour synthetically and piecework time system, limit the "working overtime voluntarily", and standardize overwork procedures. In addition, it should break the restriction of employing units' identities and industries, make unified vacation measures, which apply to all workers, regulate the applicable conditions, vacation time, rest to another time, and shift and fully implement. At the same time, the competent authority should strengthen ties and coordinate with Civil Law and Criminal Law and other laws to increase the illegal cost of employing units from the norms, sanctions, relief and other specific provisions. To reduce the burden of proof of workers for working overtime, labor arbitration institutions and courts can do something in the claims of workers to get overtime pay.

Second, the thorny wages payment rule, which has fallen into the game of multi-sectors' interests for years, reflects the difficulty in protecting workers' rights and interests. The wages payment rule should be made as soon as possible; the salary basic design principles should be set up as soon as possible; such that basic salary accounts for a smaller proportion and the overtime wages and allowances account for a bigger proportion should be solved; the minimum wage does not cover overtime wages and various forms of state subsidies; payment problems like overwork and special working time shall be clarified.

Third, the labor supervision department should enhance law enforcement and punishment. On the one hand, Labor Supervision Department should investigate, obtain evidence, strictly enforce the law, and then make severe punishment once they receive the report from workers. On the other hand, except for examining and inspecting employing units on regular and irregular, Labor Supervision Department should pay special attention to them who happen to have death from overwork, and then take the initiative to intervene, know other workers' conditions, and take measures based on law. What's more, the blacklist system can be set up and the employing units, asking overwork illegally, will be exposed publicly so as to degrade their social reputation and evaluation. Fourth, the government should further streamline administration and delegate power to lower levels, reduce various taxes and fees and lower the operating cost and burden and give the enterprises a better living environment.

\subsection{Trade Unions Should Take Active Actions}

Trade Union Law of our country has granted the trade union rights of representative, maintenance and the rights to negotiate, participate, and supervise, etc. As to protecting workers' right to rest, trade union can not only take active actions, but also achieve a lot. First of all, trade unions at all levels should actively participate in drafting and implementing of laws and regulation, policies, plans and make a strong voice to protect workers' interests generally. Trade unions, on behalf of workers, should negotiate with employers about working hours, wages and other issues and participate in business management according to the law. Besides, to perform supervision function according to law, the trade union should examine employers' condition of implementing Labor Law. Once workers' legitimate rights and interests are infringed, trade unions can provide help, support and even on behalf of workers to safeguard legal rights.

Earlier this year, Guo Jun, secretary of Secretariat of All-China Federation of Labor, minister of Legal Work Department, criticized some companies, like Foxconn asking their employees to work overtime for quite some time, for damaging labors' rights and interests. This act has greatly changed the image of trade unions, issued a powerful voice. Only by taking active actions can trade unions improve their status, which is the basis to achieve a lot. The Author hopes that trade unions at all levels can take this opportunity to make more powerful voice in regard to workers' legitimate rights and interests.

\subsection{Enterprises and Workers Should Reach a Consensus on the Issue of the Right to Rest}

To maintain the sustainable development, whether enterprises or workers, it is necessary to reach a consensus on the issue of the right to rest. With the transformation and upgrading of the economy of our country, enterprises must adjust and change the existing mode of employment.

In recent years, more and more phenomenon of "labor shortage" in our country has shown that enterprises surviving on the way of extending working time, squeezing workers physical strength, are unable to recruit their favorite employees. What's more, just let workers work overload is a short-sighted behavior, which is equal to kill the goose that lays the golden eggs.

Therefore, enterprises should accelerate transformation and upgrading itself, have the courage to innovate, and enhance the core competitiveness. For workers, they should fully understand the importance of the right to rest; the health is the premise of everything; life is only once and the spiritual and physical rest is not only conducive to improving the efficiency and innovation, but also beneficial for their development in the long run. The 
employees should have the courage to say no when their own right to rest is infracted. Only if we unite, there is the possibility of changing the status quo.

4.4 Government Departments Should Develop Ideas, Explore and Establish the Coordination Mechanism among Labor Administrative Departments, Social Insurance Agencies and Medical Institutions

The coordination mechanism can be set up in the forms of policy or regulation to implement. According to the current laws and regulation, the death, as long as taking place in the workplace, regardless of what kind of reasons, can be included into the injury insurance. Therefore, the author suggest that the injury identification department, once finding the labor's death caused by overwork in the process of determining work-related injuries, should inform the labor supervision department initiatively and timely. And medical institutions will fully understand the patient's state of the illness in the process of diagnosis and treatment. In case that labors are hospitalized or die from overwork, doctors should mark in the medical insurance information. Medical insurance sector can collect and analyze the usage of medical insurance fund through technical means, and inform the labor supervision department of the workers' information of overwork and their employing units. In these two cases, the active enforcement inspection by the labor supervision department can realize the supervision of the employing units.

\section{Copyrights}

Copyright for this article is retained by the author(s), with first publication rights granted to the journal.

This is an open-access article distributed under the terms and conditions of the Creative Commons Attribution license (http://creativecommons.org/licenses/by/4.0/). 